\title{
Distinct requirements for activation-induced cell surface expression of preformed Fas/CD95 ligand and cytolytic granule markers in $\mathrm{T}$ cells
}

\author{
D Kassahn ${ }^{1}$, U Nachbur ${ }^{1}$, S Conus ${ }^{2}$, O Micheau ${ }^{3}$, P Schneider ${ }^{4}$, H-U Simon ${ }^{2}$ and T Brunner ${ }^{\star, 1}$
}

Fas (CD95/Apo-1) ligand is a potent inducer of apoptosis and one of the major killing effector mechanisms of cytotoxic T cells. Thus, Fas ligand activity has to be tightly regulated, involving various transcriptional and post-transcriptional processes. For example, preformed Fas ligand is stored in secretory lysosomes of activated T cells, and rapidly released by degranulation upon reactivation. In this study, we analyzed the minimal requirements for activation-induced degranulation of Fas ligand. $T$ cell receptor activation can be mimicked by calcium ionophore and phorbol ester. Unexpectedly, we found that stimulation with phorbol ester alone is sufficient to trigger Fas ligand release, whereas calcium ionophore is neither sufficient nor necessary. The relevance of this process was confirmed in primary $\mathrm{CD}^{+}$and $\mathrm{CD}^{+}{ }^{+} \mathrm{T}$ cells and NK cells. Although the activation of protein kinase(s) was absolutely required for Fas ligand degranulation, protein kinase $\mathrm{C}$ or $\mathbf{A}$ were not involved. Previous reports have shown that preformed Fas ligand co-localizes with other markers of cytolytic granules. We found, however, that the activationinduced degranulation of Fas ligand has distinct requirements and involves different mechanisms than those of the granule markers CD63 and CD107a/Lamp-1. We conclude that activation-induced degranulation of Fas ligand in cytotoxic lymphocytes is differently regulated than other classical cytotoxic granule proteins.

Cell Death and Differentiation (2009) 16, 115-124; doi:10.1038/cdd.2008.133; published online 12 September 2008

Fas (CD95/Apo-1) ligand (FasL) is a member of the TNF family of death factors. FasL is inducibly expressed on activated $\mathrm{T}$ cells and natural killer (NK) cells, but also on various non-lymphoid hematopoietic cells and tissue cells. Upon interaction with Fas, its cognate receptor, Fas ligand potently induces apoptosis in sensitive target cells. FasL/ Fas-induced apoptosis has a major function in various immunological processes, including maintenance of cellular homeostasis, cell-mediated cytotoxicity as well as immune privilege. $^{1,2}$

FasL-mediated target cell apoptosis and tissue destruction has also been associated with various forms of immunopathology, including acute graft-versus-host disease and hepatitis. ${ }^{1,3}$ As many tissue cells express high levels of Fas and are exquisitely sensitive to FasL-induced cell death, FasL expression must be tightly regulated. A crucial element in the control of activation-induced FasL expression and function is its transcriptional regulation by various transcription factors. In particular, numerous reports have demonstrated an important function for the transcription factors $\mathrm{NF}_{\kappa} \mathrm{B}$, NFAT, and EGR2 and- 3 in this process (reviewed in Kavurma and Khachigian ${ }^{4}$ ). The activation of these transcription factors and thereby the induction of the FasL promoter is directly or indirectly controlled by protein kinases and the $\mathrm{Ca}^{2+} /$ calmodulinactivated phosphatase calcineurin. Consequently, $\mathrm{T}$ cell receptor-induced FasL induction can be mimicked by stimulation with phorbol ester and calcium ionophore, and is efficiently blocked by inhibitors of protein kinases or cyclosporine $A(C s A)$, which inhibits calcineurin phosphatase activity. ${ }^{5}$

Besides the important function of FasL transcription in the control of its cytotoxic activity, there is accumulating evidence for post-transcriptional regulation of FasL expression. These include enhancement of FasL activity by insertion and clustering in so-called membrane rafts ${ }^{5}$ and downregulation of functional FasL on the plasma membrane by proteolytic cleavage. ${ }^{6}$ Furthermore, it was shown that FasL is accumulated in activated $T$ cells in granule-like structures and can be rapidly released in a protein synthesis-independent manner upon restimulation. ${ }^{3,7,8}$ These FasL-containing granule-like structures likely represent so-called secretory lysosomes with important functions in degranulation-induced cytotoxicity in T cells. Interestingly, Griffiths and co-workers ${ }^{7,8}$ have recently shown that intracellular FasL co-localizes with other markers of secretory lysosomes, such as CD107a/Lamp-1, CD63, perforin and granzymes. The co-localization of FasL, perforin and granzymes within the same subcellular structures has lead to the notion that the simultaneous delivery of these apoptosis-inducing molecules into the immunological synapse between effector and target cells may result in a more efficient and rapid target cell killing. ${ }^{7}$ The intracellular accumulation of FasL appears to be tightly regulated by the

${ }^{1}$ Division of Immunopathology, Institute of Pathology, University of Bern, Bern, Switzerland; ${ }^{2}$ Institute of Pharmacology, University of Bern, Bern, Switzerland; ${ }^{3}$ INSERM, U866, University of Bourgogne, Dijon, France and ${ }^{4}$ Institute of Biochemistry, University of Lausanne, Switzerland

${ }^{*}$ Corresponding author: T Brunner, Division of Immunopathology, Institute of Pathology, University of Bern, Murtenstrasse 31, PO Box 62, 3010 Bern, Switzerland. Tel: + 413163249 71; Fax: + 413138187 64; E-mail: tbrunner@pathology.unibe.ch

Keywords: cytotoxic T cells; Fas ligand; cytotoxic granules; degranulation; protein kinases

Abbreviations: Bim I, bisindolylmaleimide I (Gö6850); CsA, cyclosporin A; FasL, Fas ligand; LAK, lymphokine-activated killer cells; NK, natural killer; PKA, protein kinase A; PKC, protein kinase C; PMA, phorbol myristate acetate; TCR, T cell receptor

Received 04.3.08; revised 16.6.08; accepted 30.7.08; Edited by JP Medema; published online 12.9.08 
proline-rich domain in its cytoplasmic tail and interacting molecules. $^{7,8}$ Consequently, mutants of FasL lacking this proline-rich domain fail to sort FasL into secretory vesicles and display constitutive cell surface expression of FasL.

The degranulation of secretory lysosomes and associated Fas $L$ can be triggered by restimulation of the $T$ cell receptor. ${ }^{3,9}$ The activation-induced movement of secretory lysosomes towards the cell surface and into the immunological synapse proceeds along the microtubules, whereas the last step to plasma membrane appears to be actin filament-dependent. ${ }^{10}$ However, the exact signaling events initiated by the $\mathrm{T}$ cell receptor leading to the degranulation and cell surface expression of FasL are largely unknown. In particular, it is not clear to what extent $\mathrm{T}$ cell receptor-induced kinase pathways, as simulated by addition of phorbol ester, and increase in intracellular $\mathrm{Ca}^{2+}$, simulated by calcium ionophor, contribute to this process.

Here, we show that stimulation of T cells with phorbol ester but not ionomycin is sufficient to rapidly induce FasL degranulation and cell surface expression. Phorbol esterinduced degranulation was found to depend on protein transportation mechanisms and protein kinase activity but was independent on protein kinase $\mathrm{C}(\mathrm{PKC})$ or PKA activity. Interestingly, although FasL co-localized with CD63 or CD107a/Lamp-1 to some degree, only FasL degranulation was induced by phorbol ester, whereas degranulation of CD63 and CD107a/Lamp-1 required activation by both phorbol ester and ionomycin. These data suggest that the signal transduction events regulating Fas $L$ degranulation from intracellular stores are different from those controlling the degranulation of classical cytotoxic granule proteins.

\section{Results}

Murine $T$ cell blasts store preformed Fas $L$ and release it to the cell surface upon activation. To investigate how the activation-induced release of preformed FasL from its intracellular stores to the cell surface is regulated in T cells, we employed murine $T$ cell blasts as a model system. Culture of activated murine $\mathrm{T}$ cells in IL-2-containing medium for 7 days leads to expression and accumulation of FasL in intracellular stores. Immunohistochemical detection of FasL revealed that $\mathrm{T}$ cell blasts store FasL in granule-like structures (Figure 1a), confirming previous observation by us $^{3}$ and others. ${ }^{7}$ A similar pattern was observed when cells were stained for the granule marker CD107a/Lamp-1 (Figure 1b). Re-stimulation of these $T$ cells with platebound anti-CD3 lead to a rapid degranulation and expression of functional FasL on the cell surface, as detected by killing of Fas-sensitive target cells (Figure 2a). This cell-mediated cytotoxicity was entirely FasL-mediated as neutralization of FasL completely abrogated target cell killing (Figure 2b). To assess the contribution of de novo synthesized versus preformed and granule-stored FasL in this process, activation-induced FasL transcription was blocked by cyclosporin A (CsA). ${ }^{3}$ Figure 2c shows anti-CD3-induced FasL-mediated killing was only partially blocked by CsA, indicating that a substantial proportion of FasL killing activity was mediated by preformed and degranulated FasL.
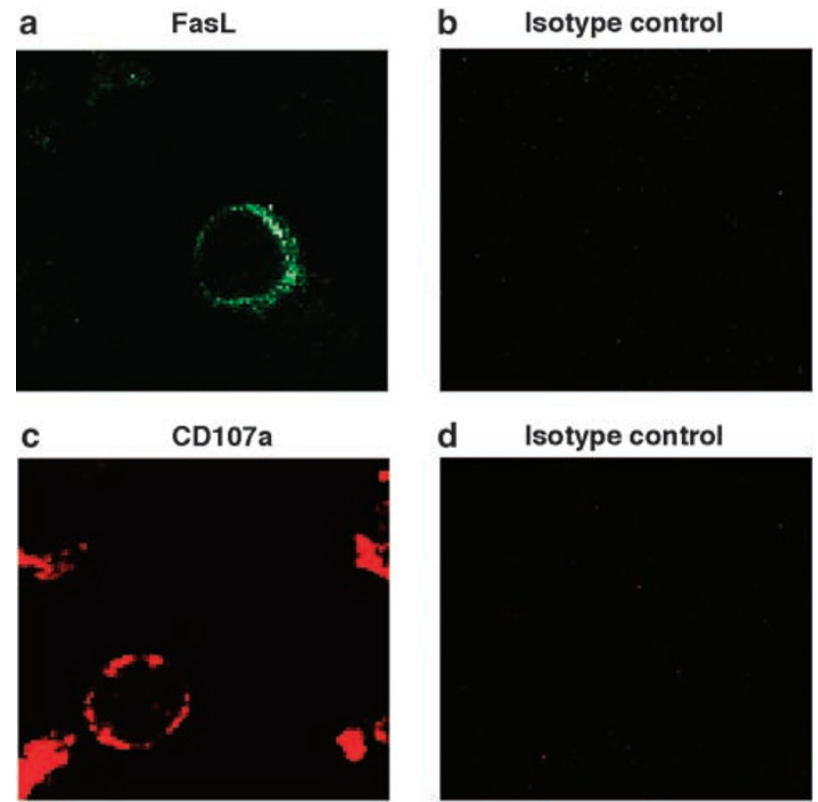

d Isotype control

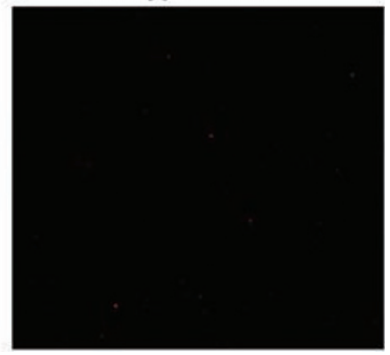

Figure 1 Murine T cell blasts store preformed FasL in granule-like structures. Murine T cell blasts were stained intracellularly with either anti-FasL (a) or isotype control (b), or the granule marker CD107a (c) and the corresponding isotype control (d). Images were taken by confocal microscopy. A typical example of FasL- and CD107a-positive cells out of four individual experiments is shown

Phorbol ester is sufficient to trigger release of preformed FasL from intracellular stores. T cell receptor (TCR)-induced $\mathrm{T}$ lymphocyte activation can be simulated by phorbol ester and ionomycin ${ }^{11,12}$ activating the protein kinase pathways and the release of intracellular calcium, respectively. Accordingly, we observed that phorbol myristate acetate (PMA) plus ionomycin efficiently induced functional FasL cell surface expression (Figure 2a). To investigate whether both the kinase pathway (PMA) and the calcium pathway (ionomycin) are required for inducing cell surface expression of preformed FasL, $T$ cell blasts were stimulated with either PMA or ionomycin alone. Surprisingly, we observed that PMA but not ionomycin alone was sufficient to trigger FasL-mediated cytotoxicity (Figure 2a). Critically, although both de novo synthesized as well as preformed FasL contributed to anti-CD3-mediated FasL cell surface expression, PMA-induced FasL killing activity was entirely mediated by degranulation of preformed FasL, as its activity was not blocked by CsA (Figure 2c). Interestingly, CsA blocked anti-CD3-induced FasL activity precisely to the level of PMA-induced activity. This indicates that degranulation of preformed FasL occurs in response to both TCR stimulation and to stimulation with PMA. In agreement with this finding we observed that anti-CD3 stimulation induced FasL transcription, which was blocked by $\mathrm{CsA}^{13,14}$ whereas PMA failed to do so (Figure 2d).

Phorbol ester-induced FasL degranulation is dependent on intracellular transportation mechanisms. The degranulation of secretory vesicles has been previously reported to depend on cellular transportation mechanisms and actin polymerization (reviewed in Stinchcombe and 

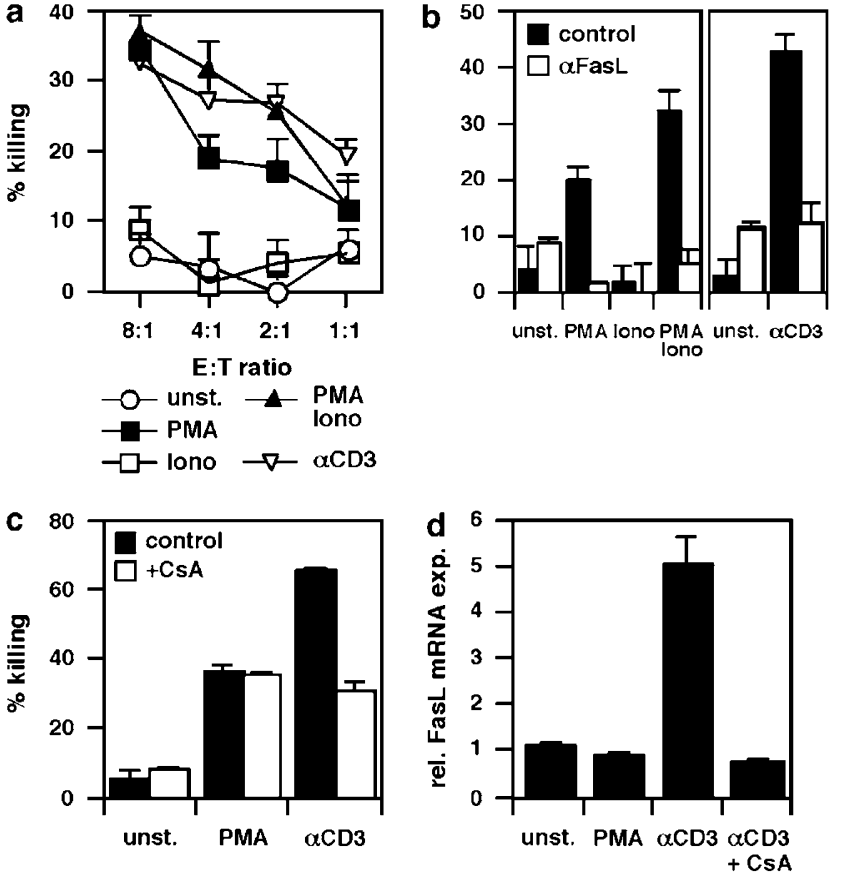

Figure 2 PMA induces FasL cell surface expression independent of de novo synthesis. (a) Murine T cell blasts were stimulated with either $3 \mu \mathrm{g} / \mathrm{ml}$ plate-bound anti-CD3, $20 \mathrm{ng} / \mathrm{ml} \mathrm{PMA}$ and $/$ or $500 \mathrm{ng} / \mathrm{ml}$ ionomycin, or left untreated before they were co-cultured at different effector/target $(E / T)$ ratios with Fas-sensitive target cells (L1210Fas). After $6 \mathrm{~h}$ target cell killing was assessed by the induction of DNA fragmentation in target cells. (b) Specificity of killing was confirmed by neutralizing FasL with anti-FasL antibodies at an $E / T$ ratio of $4: 1$. (c) FasL de novo synthesis was inhibited by pre-treatment of $\mathrm{T}$ cell blasts with $200 \mathrm{ng} / \mathrm{ml}$ cyclosporin A (CSA) for $30 \mathrm{~min}$ before stimulation. Cells were co-cultured together with Fas-sensitive target cells at an E/T ratio of $4: 1$ for $6 \mathrm{~h}$. A typical experiment out of five is shown. (d) T cell blasts were stimulated for $6 \mathrm{~h}$ with PMA or anti-CD3 and FasL mRNA expression was measured by quantitative RT-PCR. Anti-CD3-induced FasL transcription was blocked by pre-treatment with $200 \mathrm{ng} / \mathrm{ml} \mathrm{CsA}$. A typical experiment out of two is shown (mean values of triplicates \pm S.D.)

Griffiths; Clark and Griffiths ${ }^{15,16}$ ). We therefore assessed whether PMA-induced degranulation of preformed FasL would also rely on the same mechanisms. Both, PMA- and anti-CD3-induced FasL cell surface expression was efficiently blocked by brefeldin A (Figure 3a), a relatively broad pre- and post-Golgi protein transportation inhibitor, demonstrating that general protein transportation mechanisms are involved in activation-induced FasL degranulation. Similar to brefeldin A, latrunculin B completely blocked PMA- and anti-CD3-induced functional FasL cell surface expression (Figure $3 b$ ), supporting a function for actin polymerizationdependent mechanisms in the activation-induced degranulation of FasL-containing secretory vesicles.

More recently, activation of myosin IIA, which is blocked by blebbistatin or the myosin light chain kinase inhibitor ML-7, has been implicated in activation-induced cytolytic granule exocytosis. ${ }^{17}$ Surprisingly, however, we found that neither blebbistatin nor ML-7 blocked activation-induced and PMAinduced FasL degranulation (Figure $3 \mathrm{c}$ and d).

PMA-induced FasL degranulation occurs in different lymphocyte subsets. Lectin-induced $\mathrm{T}$ cell blasts consist of
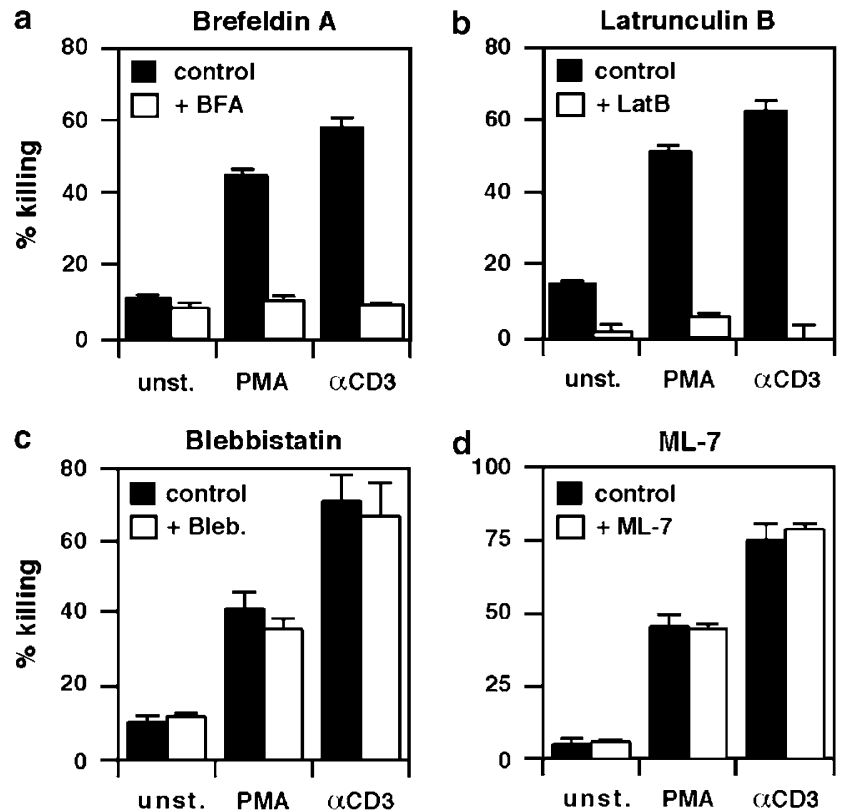

Figure 3 PMA-induced FasL cell surface expression can be blocked by protein transportation inhibitors but is independent of myosin IIA activation. Murine $\mathrm{T}$ cell blasts were either pre-incubated with (a) $1 \mu \mathrm{g} / \mathrm{ml}$ brefeldin A (BFA), (b) $2 \mu \mathrm{M}$ latrunculin B (LatB), (c) $100 \mu \mathrm{M}$ blebbistatin (Bleb) or (d) $10 \mu \mathrm{M} \mathrm{ML-7} \mathrm{for} 30 \mathrm{~min}$. Cells were then stimulated with $20 \mathrm{ng} / \mathrm{ml}$ PMA or $3 \mu \mathrm{g} / \mathrm{ml}$ plate-bound anti-CD3 or left untreated (unst.) and co-cultured with Fas-sensitive target cells $(E / T=4: 1)$. After $6 \mathrm{~h}$ target cell killing was assessed by the induction of DNA fragmentation in target cells. A typical experiment out of three is shown (mean values of triplicates \pm S.D.)

various lymphocyte subsets, including $\mathrm{CD}^{+}, \mathrm{CD}^{+}$and $\mathrm{NK}$ cells. As all subsets have been reported to express and intracellularly store FasL upon activation ${ }^{3,7}$ and to kill target cells in a FasL-dependent manner; ${ }^{18,19}$ we aimed at addressing whether PMA can induce FasL degranulation in all lymphocyte subsets. Highly purified $\mathrm{CD} 4^{+}$and $\mathrm{CD} 8^{+}$ $T$ cell blasts were stimulated with anti-CD3, PMA, ionomycin or the combination thereof. Figure $4 a$ and $b$ shows that PMA but not ionomycin alone was sufficient to induce functional FasL cell surface expression in $\mathrm{CD}^{+}{ }^{+}$as well as $\mathrm{CD} 8^{+}$ $T$ cells. PMA-induced FasL-dependent target cell killing was somewhat weaker than that induced by plate-bound antiCD3 or PMA plus ionomycin. Unlike anti-CD3- and PMA/ ionomycin-induced killing, it was however insensitive to CsA, indicating that PMA-induced cell surface expression of FasL in $\mathrm{CD}^{+}$and $\mathrm{CD}^{+}{ }^{+} \mathrm{T}$ cells is solely dependent on degranulation of preformed FasL (data not shown).

Previous reports by Bossi and Griffiths ${ }^{7}$ have shown that NK cells also store FasL in intracellular granules. We thus investigated whether PMA was also able to induce the release of preformed FasL in NK cells. In lymphokine-activated killer (LAK) cells, which contain also NK cells (data not shown), PMA but not ionomycin alone efficiently induced FasLdependent killing, which was comparable to that induced by PMA plus ionomycin (Figure 4c). This finding was confirmed in highly purified $\mathrm{DX} 5^{+} \mathrm{CD}^{-} \mathrm{NK}$ cells, where PMA but not ionomycin alone induced FasL-dependent target cell killing (Figure 4d). 

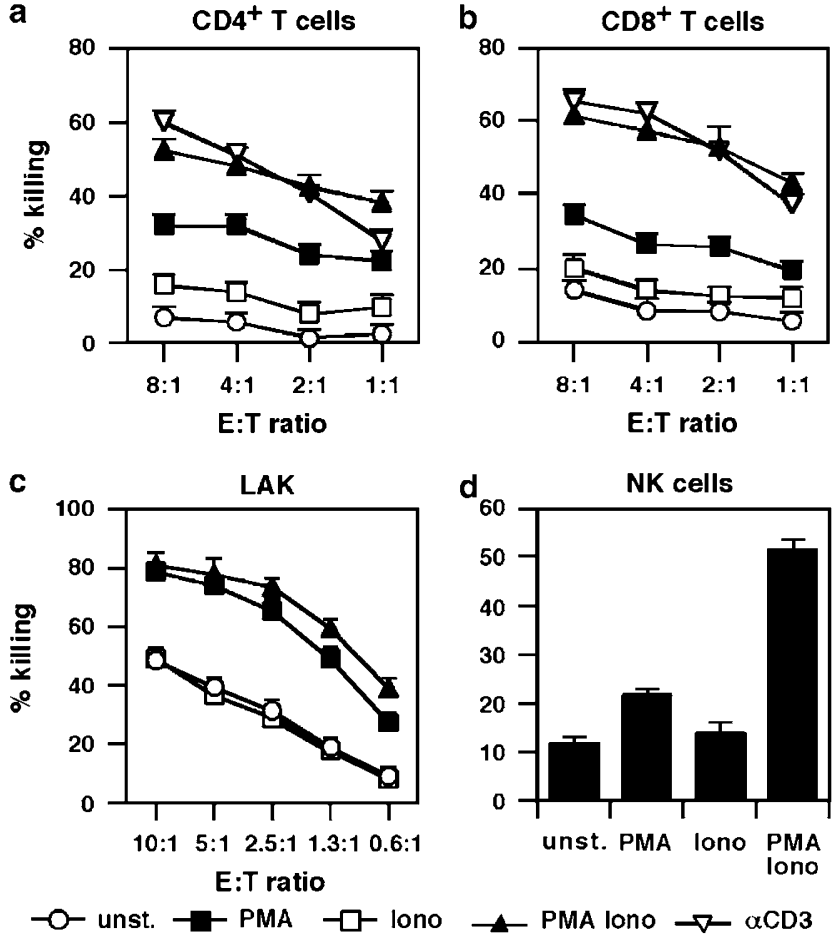

Figure 4 PMA-induced FasL degranulation occurs in different lymphocyte subsets. (a) Purified $\mathrm{CD} 4^{+}$and (b) $\mathrm{CD} 8^{+} \mathrm{T}$ cell blasts, (c) lymphokine-activated killer cells (LAK) or (d) highly purified NK cells were stimulated with either $3 \mu \mathrm{g} / \mathrm{ml}$ plate-bound anti-CD3, $20 \mathrm{ng} / \mathrm{ml}$ PMA and $/$ or $500 \mathrm{ng} / \mathrm{ml}$ ionomycin, or left untreated before they were co-cultured at different effector to target $(E / T)$ ratios with Fassensitive target cells (L1210Fas). NK cells were used at an E/T ratio of $5: 1$. After a $6 \mathrm{~h}$ target, cell killing was assessed by the induction of DNA fragmentation in target cells. All experiments were performed at least three times and in triplicates. Mean values of typical experiments \pm S.D. are shown

Phorbol ester-induced cell surface expression of FasL is dependent on protein kinases but independent of protein kinase $\mathbf{C}$ or protein kinase $\mathbf{A}$. PMA is an efficient activator of protein kinases, in particular protein kinase $\mathrm{C}$ (PKC) isoforms. $^{20}$ We thus aimed at investigating the function of protein kinases in PMA-induced release of preformed FasL. Figure $5 \mathrm{a}$ shows that K252a, a broadspectrum protein kinase inhibitor, ${ }^{21}$ efficiently blocked PMAinduced FasL-dependent killing of target cells, suggesting an important role for protein kinases in PMA-induced FasL degranulation. We next investigated a specific role for PKC in this process. PKC has been previously implicated in activation-induced FasL transcription. ${ }^{22,23}$ In addition, PKC has been involved in activation-induced degranulation of cytolytic granules. ${ }^{24}$ Surprisingly, bisindolylmaleimide I (Bim I, Gö6850), which inhibits various PKC isoforms, ${ }^{25}$ failed to block PMA-induced degranulation of preformed FasL (Figure 5b), whereas it efficiently blocked PMA/ionomycininduced NFAT reporter activation (data not shown). Similar results were obtained with another PKC inhibitor (Gö6976, data not shown), suggesting that PKC isoforms are not involved in activation-induced FasL degranulation.

PMA not only activates PKC, but leads also to the activation of other protein kinases, for example protein kinase $A$ $(\mathrm{PKA}){ }^{26}$ In addition, it has been reported that PKA share
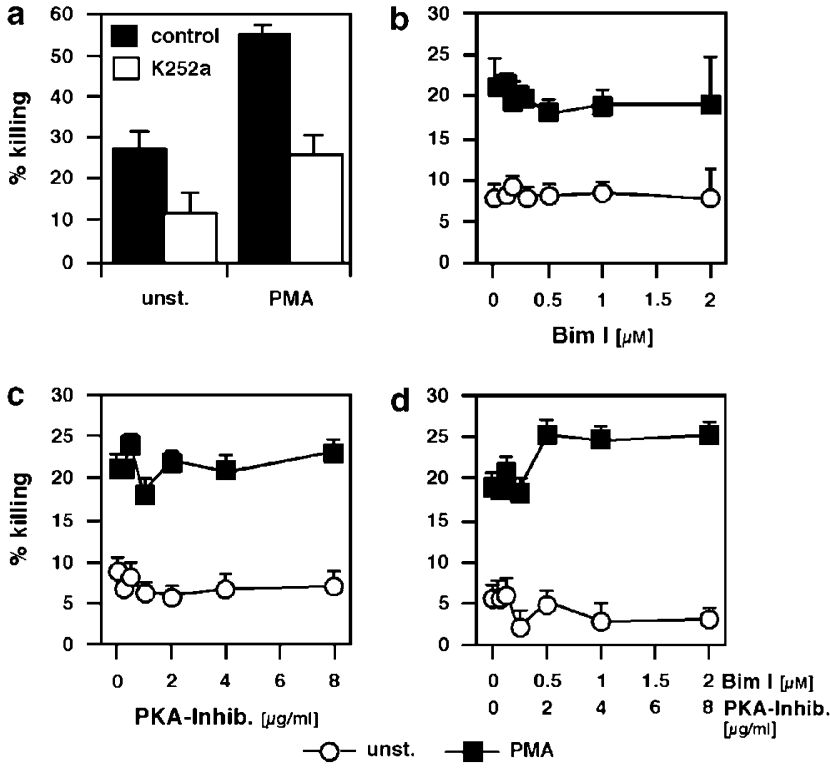

Figure 5 PMA-induced FasL cell surface expression is protein kinasedependent but independent of protein kinase $\mathrm{C}$ or $\mathrm{A}$ activation. (a) Murine $\mathrm{T}$ cell blasts were either pre-incubated with $250 \mathrm{nM}$ of the broad-spectrum kinase inhibitor K252a or left untreated (control), stimulated with $20 \mathrm{ng} / \mathrm{ml} \mathrm{PMA} \mathrm{and} \mathrm{co-cultured} \mathrm{with}$ Fas-sensitive target cells $(\mathrm{L} 1210 \mathrm{Fas})$ for $6 \mathrm{~h}(\mathrm{E}: \mathrm{T}$ ratio $=4: 1)$. Target cell killing was assessed by the induction of DNA fragmentation. (b) T cell blasts were preincubated with increasing concentrations of Bim I to inhibit PKC activity. (c) T cell blasts were pre-incubated with increasing concentrations of PKA inhibitory peptide. (d) A combination of increasing concentrations of Bim I and the PKA inhibitory peptide were used. All the inhibitors used were present throughout the whole experiment. All experiments were performed at least three times and in triplicates. Mean values of typical experiments \pm S.D. are shown

substrate specificity with PKC. ${ }^{27}$ and thus may functionally substitute PKC under certain circumstances. We therefore assessed whether an inhibitor of PKA, alone or in combination with Bim I, could inhibit PMA-induced FasL degranulation in $\mathrm{T}$ cell blasts. Figure $5 \mathrm{c}$ and $\mathrm{d}$ shows that neither the PKA inhibitor alone nor in combination with the PKC inhibitor was able to block PMA-induced FasL cell surface expression, excluding a function for both PKC isoforms and PKA in this process.

PMA induces the rapid degranulation of FasL in Jurkat cell transfectants. The experiments described above indicated that stimulation with PMA primarily triggered the release of preformed FasL from intracellular stores to the cell surface. To better investigate the kinetic and mechanism of this process, we transfected Fas-deficient Jurkat $\mathrm{T}$ cells (JOM-2) with GFP-FasL. Figure $6 a$ shows that the subcellular localization of GFP-FasL in transfected Jurkat cells was also in granule-like structures, as has been seen for endogenous FasL in murine $T$ cell blasts (Figure 1). FasLtransfected Jurkat cells seem thus to represent an adequate model system for the release of preformed FasL in primary $T$ cells. We next assessed whether stimulation with PMA was sufficient to trigger the release of the GFP-FasL fusion protein from intracellular stores. Although in transfected Jurkat cells FasL was already detectable to some extent on the cell surface of unstimulated cells, stimulation with PMA 

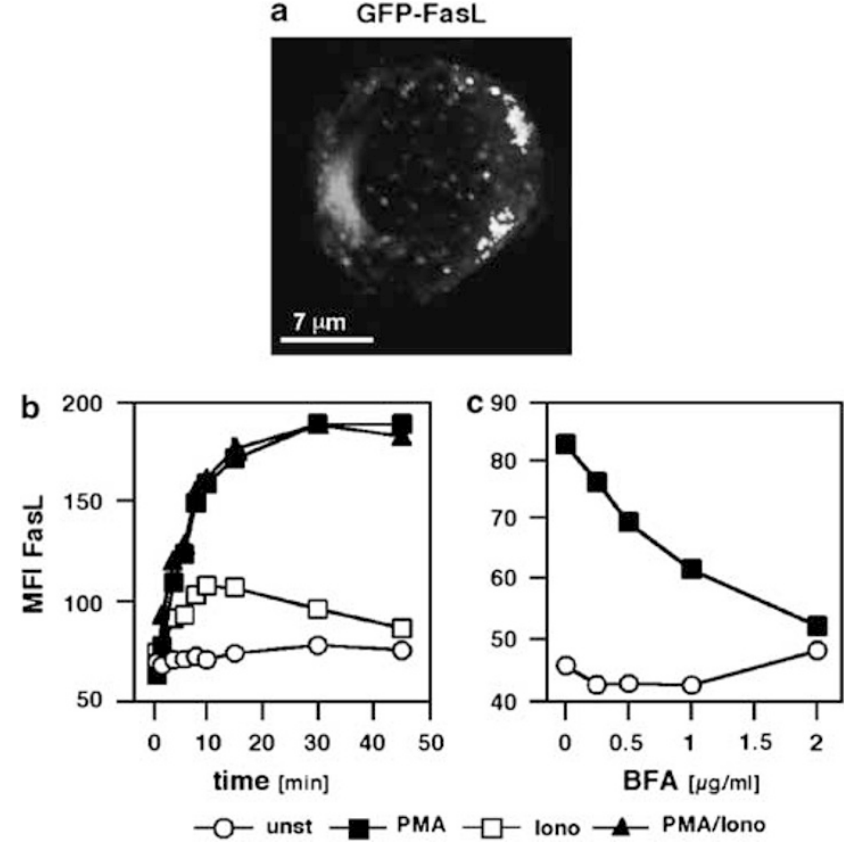

Figure 6 Rapid PMA-induced FasL degranulation in Jurkat cell transfectants. JOM-2 cells were transfected with a GFP-FasL construct. (a) A typical picture taken on a confocal microscope is shown (b) GFP-FasL-transfected cells were stimulated with $20 \mathrm{ng} / \mathrm{ml}$ PMA and/or $500 \mathrm{ng} / \mathrm{ml}$ ionomycin or left untreated (unst) for the indicated time points. Cells were stained with anti-FasL antibody and FasL cell surface expression was analyzed by flow cytometry. Mean fluorescence intensity of FasL staining in GFP-positive cells is shown. (c) FasL-transfected cells were preincubated with increasing concentrations of brefeldin $A$ (BFA) before stimulation for 30 min. FasL cell surface expression was measured by flow cytometry. A typical experiment out of three is shown

plus ionomycin or PMA alone induced a rapid increase of FasL cell surface expression, as detected by flow cytometry (Figure 6b). PMA-induced degranulation of FasL was very rapid reaching half maximal levels already after $10 \mathrm{~min}$ and maximal levels after $30 \mathrm{~min}$. In marked contrast and agreement with our findings in primary $T$ cells, no substantial increase in FasL cell surface expression was observed after stimulation with ionomycin alone. Similar to the release of endogenous FasL in T cell blasts, PMA-induced degranulation of GFP-FasL in transfectants was also blocked by brefeldin A (Figure 6c). Thus, identical mechanisms seem to regulate the release of preformed FasL in primary murine $\mathrm{T}$ cells and FasL-transfected Jurkat cells.

The release of FasL and the secretory granule markers CD63 and CD107a/Lamp-1 is differentially regulated. Previous reports have shown that preformed FasL is stored in secretory lysosomes and co-localizes with other granule proteins, such as perforin, granzyme $\mathrm{B}$, cathepsin D, CD63 and CD107a/Lamp-1.,8 Similar to FasL, CD63 can be detected on the cell surface after activation-induced release from intracellular stores. ${ }^{7}$ We thus assessed whether identical mechanisms would lead to the release of FasL and CD63. GFP-FasL-transfected Jurkat cells (JOM-2) were thus stimulated with PMA, ionomycin or the combination thereof, and FasL and CD63 cell surface expression was detected by flow cytometry. As described above, we

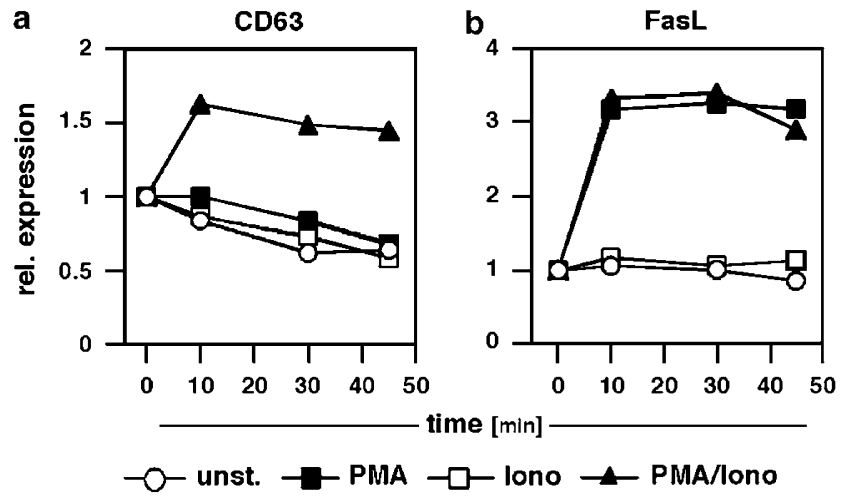

Figure 7 PMA induces FasL but not CD63 cell surface expression. JOM-2 cells were transfected with GFP-FasL and stimulated with $20 \mathrm{ng} / \mathrm{ml} \mathrm{PMA} \mathrm{and} / \mathrm{or} 500 \mathrm{ng} / \mathrm{ml}$ ionomycin or left untreated (unst) for the indicated time points. Cells were stained with either (a) anti-CD63 or (b) anti-FasL antibodies, and cell surface expression was analyzed by flow cytometry. Relative fluorescence intensity is shown (values normalized to unstimulated controls)

observed a rapid release and increase in cell surface expression of FasL after stimulation with PMA alone or PMA plus ionomycin (Figure 7b). In marked contrast, PMA alone failed to induce the release of the secretory granule marker CD63, and only the combination of PMA and ionomycin resulted in increased CD63 cell surface expression (Figure 7a). This data suggest different requirements and mechanisms for the activation-induced release of FasL and CD63 from intracellular stores.

We therefore analyzed the subcellular localization of FasL and CD63 using confocal microscopy. Figure 8a shows that in transfected Jurkat cells (JOM-2), both GFP-FasL and endogenous CD63 localize in cytoplasmic granule-like structures. The overlay of the two signals, however, revealed only a minimal co-localization of FasL and CD63. Clearly, granules containing only FasL or CD63 were detectable, indicating that FasL and CD63 do not necessarily co-localize. In marked contrast, when GFP-FasL-transfected Jurkat cells were stained with anti-FasL an expected perfect co-localization for the two signals was observed (Figure 8b). A similar pattern was also seen for endogenous FasL and CD107a/Lamp-1 in murine T cell blasts. Although both FasL and CD107a stained with a granular pattern, there was only minimal co-localization (Figure 8c).

To further confirm that activation-induced degranulation of preformed FasL is differentially regulated from other granule proteins and to assess the relevance of this finding in primary cells, we also examined the activation-induced release of CD63 and CD107a/Lamp-1 in primary human T cell blasts. As already shown in primary mouse T cells and FasL-transfected Jurkat cells, PMA alone was sufficient to trigger the release of preformed FasL in human T cell blasts (Figure 9a). In contrast, surface expression of CD63 and CD107a required the simultaneous stimulation of primary human $\mathrm{T}$ cell blasts with PMA and ionomycin (Figure 9b and c). Interestingly, although brefeldin A efficiently blocked activation-induced cell surface expression of FasL (Figures 3a, 6c and Wasem et al. ${ }^{3}$ ), it had no effect on the release of CD107a (Figure 9c) or CD63 (data not shown), indicating different mechanisms of 
a
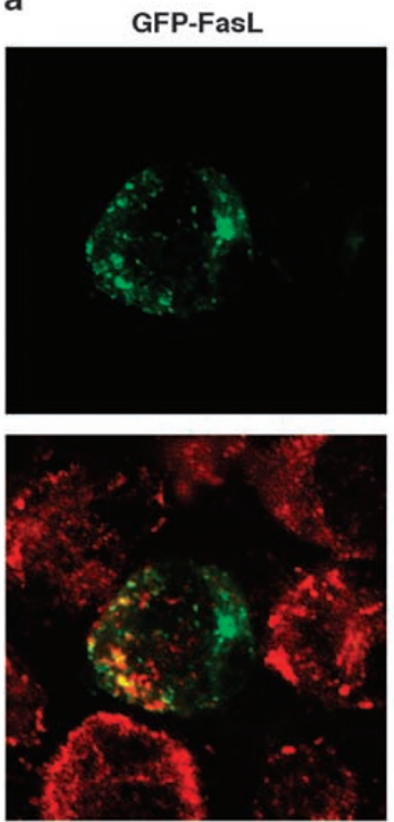

overlay
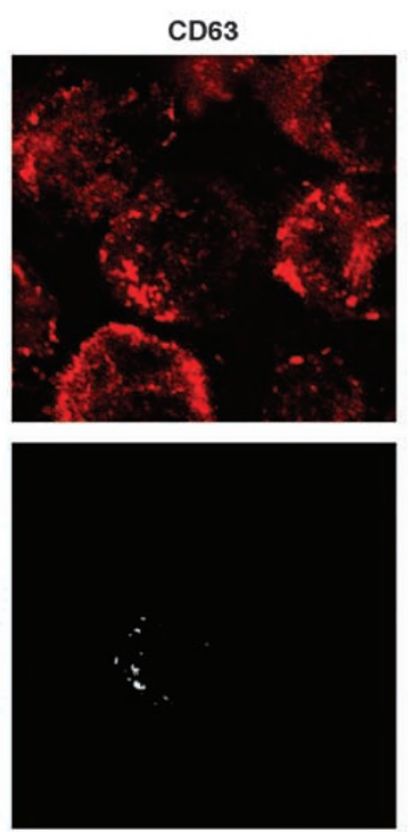

colocalization

FasL
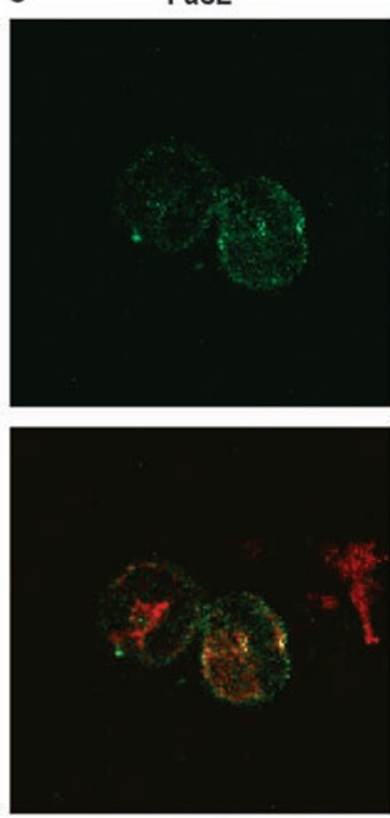

overlay b
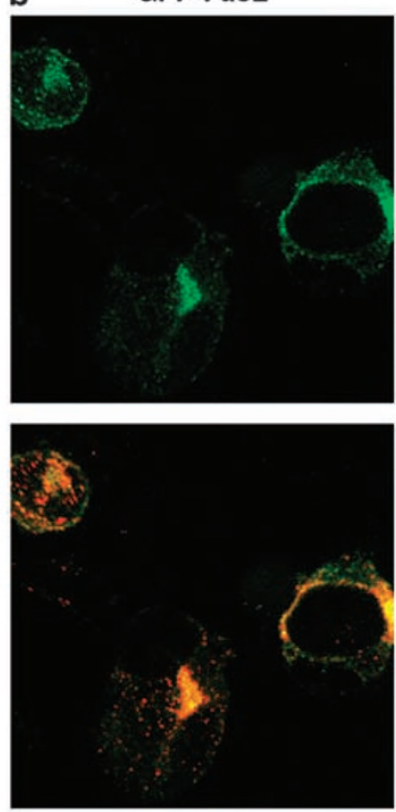

overlay

CD107a
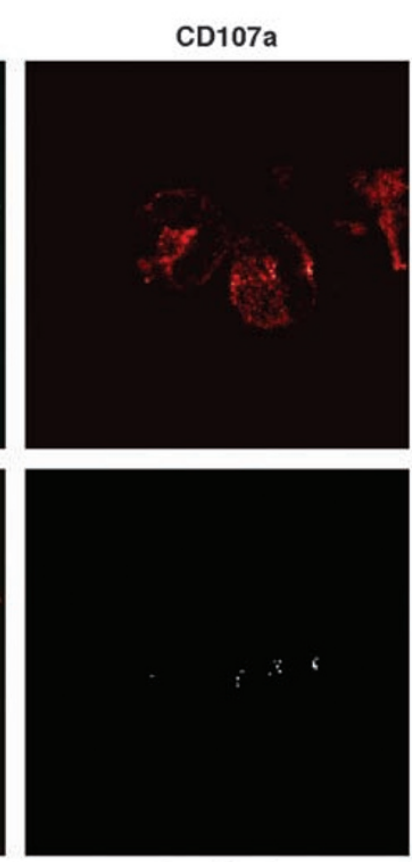

colocalization
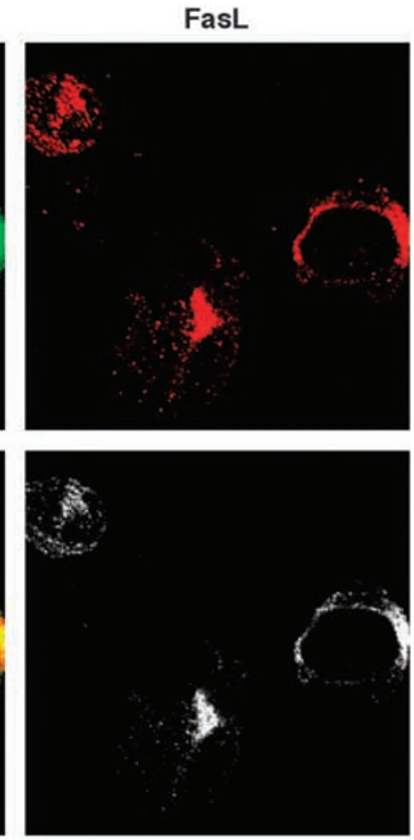

colocalization

Figure 8 CD63, CD107a and FasL localize to different subcellular compartments. JOM-2 cells were transfected with GFP-FasL (green) and stained intracellularly for (a) $\mathrm{CD} 63$ or, as positive control, for (b) FasL (red). Images were taken on a confocal microscope. Co-localization was analyzed using the Imaris software. Co-localization values for GFP-FasL and CD63 $P=0.232$; co-localization values for GFP-FasL and FasL staining $P=0.742$. (c) Murine T cell blasts were stained intracellularly for FasL (green) and $\mathrm{CD107a}$ (red). Overlay and co-localization are shown. Co-localization values for FasL and CD107a $P=0.144$

activation-induced release between FasL and CD107a or CD63. Furthermore, although the myosin IIA activation inhibitor ML-7 blocked at least partially activation-induced release of CD63 (data not shown) and CD107a (Figure 9d and ${ }^{17}$ ), FasL degranulation was insensitive to this inhibitor (Figure 3d). Comparable results were also obtained with blebbistatin (Figure 3c, and data not shown).

\section{Discussion}

Previous reports, including ours, have shown that cytotoxic $\mathrm{T}$ lymphocytes accumulate preformed FasL in granule-like structures, often co-localizing with markers of secretory lysosomes. ${ }^{7,8,16,28}$ In this study, we analyzed the minimal signals required for the activation-induced release of 

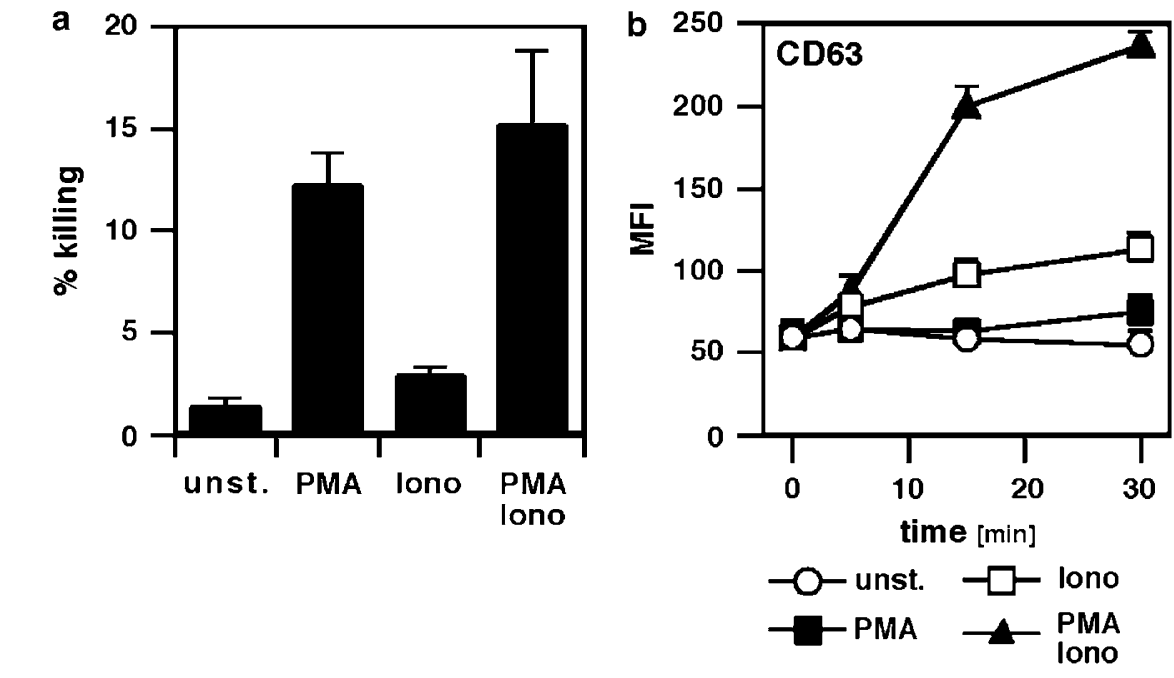

C

control
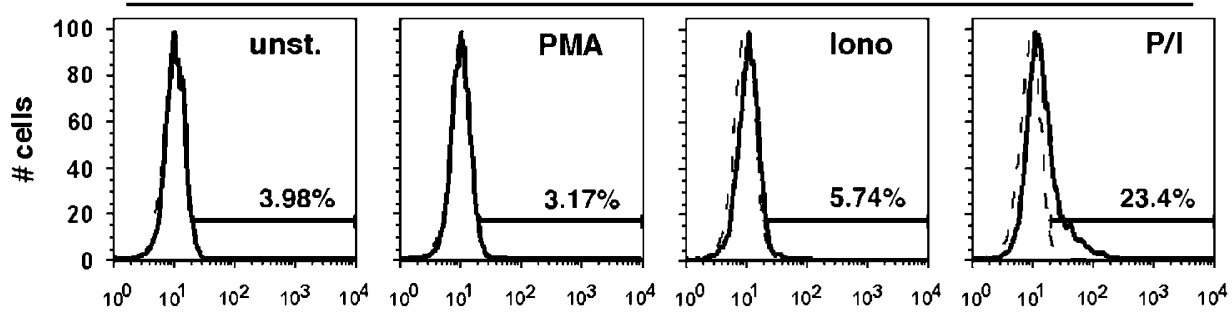

+BFA

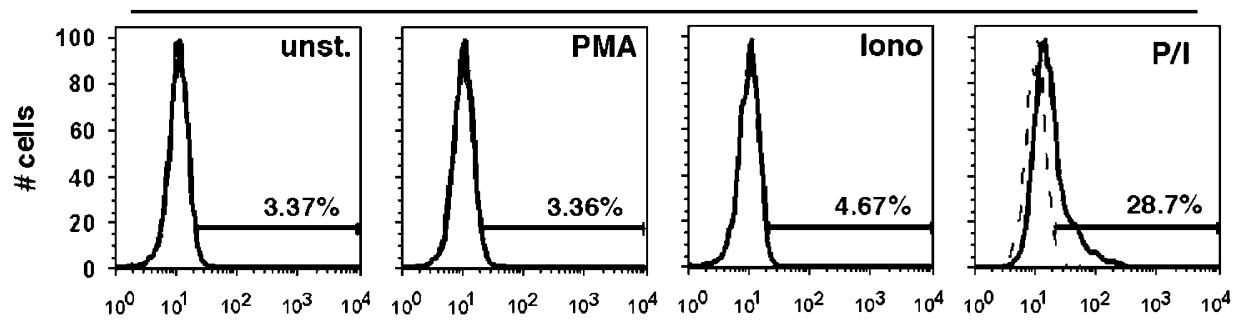

d

control
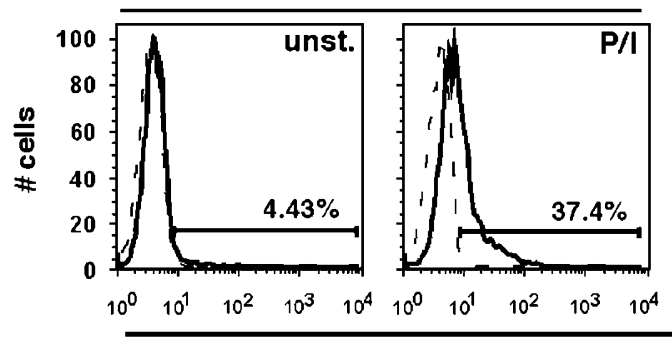

+ML-7

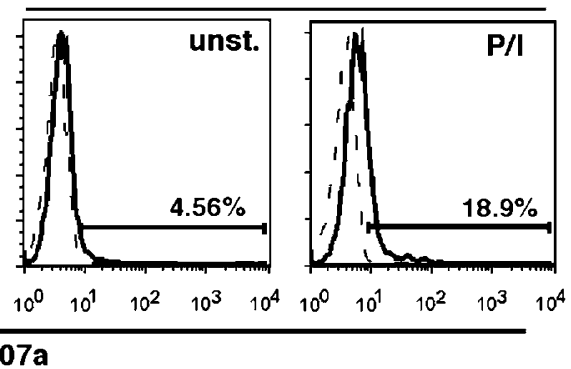

Figure 9 Differential induction of CD63, CD107a and FasL cell surface expression. Human T cell blasts were stimulated with $20 \mathrm{ng} / \mathrm{ml} \mathrm{PMA} \mathrm{and/or} 500 \mathrm{ng} / \mathrm{ml}$ ionomycin, or left untreated (unst) and FasL cell surface expression was measured by killing of Fas-sensitive target cells (a) or CD63 cell surface expression was measured by flow cytometry (b). Mean fluorescence intensity (MFI) is shown. (c) Induction of CD107a cell surface expression was measured by flow cytometry. The dashed line shows the isotype control, the bold line shows CD107a staining. In the lower panel, cells were incubated with $1 \mu \mathrm{g} / \mathrm{ml}$ brefeldin A (BFA) before stimulation. (d) Human T cell blasts were pre-incubated with or without ML-7 and CD107a and cell surface expression was measured. Typical experiments out of three are shown

preformed FasL. TCR-induced cell activation can be simulated by PMA and ionomycin. ${ }^{11,12}$ Interestingly, we have seen that PMA alone is sufficient to induce degranulation of preformed FasL. This was unexpected as stimulation with both PMA and ionomycin is required for inducing the release of lytic granule markers. ${ }^{11,24}$ In marked contrast to FasL degranulation both the activation of protein kinases and an increase in intracellular calcium is required for activationinduced FasL transcription or the release of CD63- and CD107a-containing secretory granules. This is in agreement 
with previous reports that described the need for both PMA and ionomycin for the activation-induced release of CD63, CD107a, perforin and granzymes ${ }^{11,12,24}$ (and own results). Our findings are further supported by the observation that weak TCR signals, that do not elicit a detectable increase in intracellular calcium, induce FasL-mediated killing, whereas strong TCR activation also promote perforin/granzymemediated cytotoxicity. ${ }^{29}$ Interestingly, it was found that the $\mathrm{T}$ cell clone used for this study constitutively expressed FasL. Accordingly, the authors suggested that weak TCR stimulation triggers the release of preformed and intracellularly stored FasL, whereas the release of perforin would require a strong TCR signal and an increase in intracellular calcium. ${ }^{29}$ Furthermore, it has been shown that altered-self peptide ligands activate the Fas-dependent killing pathway in the absence of perforin-mediated cytotoxicity. ${ }^{30,31}$ These data suggest that the degranulation process of preformed FasL on one hand and markers of classical cytotoxic granules on the other hand are regulated in a substantially different manner. Our results show a consistent picture that different molecular mechanisms control the activation-induced release of FasL versus cytotoxic granule markers. For example we have seen that the general protein transport inhibitor brefeldin A efficiently blocks degranulation of FasL, whereas it does not affect release of CD107a (Figures 3a, 6c and 9b), or perforin and granzymes. ${ }^{32}$ In marked contrast, myosin light chain activation, blocked by blebbistatin and ML-7, seem to be required for the release of classical cytotoxic granules ${ }^{17}$ but not of preformed FasL (Figure $3 c$ and d).

These findings suggest that either the release of proteins within the same secretory granules is differentially regulated or that FasL and other markers are not stored in the same type of secretory granules. Indeed, we have seen that in Jurkat cell transfectants FasL only minimally co-localizes with the secretory lysosome marker CD63 (Figure 8a). Similar results were recently reported by $\mathrm{He}$ and Ostergaard $^{9}$ in primary $T$ cells. These results contrast to some extent with previous findings by Griffiths and co-workers ${ }^{7,8}$ who described a co-localization of FasL and markers of cytotoxic granules in various lymphocyte subsets. These discrepancies are difficult to reconcile. One possibility may be that co-localization of individual lysosomal markers was analyzed at different time points after primary $\mathrm{T}$ cell activation and in various cell lines. The sorting of FasL and the other cytolytic granule markers studied may thus differ in different cell types and depending on the activation status of the cytotoxic lymphocytes. Interestingly, however, we never noticed a major difference in the ability of PMA to induce FasL degranulation in day 7 or day 14 $T$ cell blasts, apart from a different ratio between preformed FasL and de novo synthesized protein (data not shown). Another critical aspect may be that the recycling of CD63, CD107a and FasL by endocytosis and thus the intracellular localization may be different under these distinct conditions. Whereas CD63 and CD107a are known to be transiently secreted to the plasma membrane from where they are recycled to the secretory lysosomes by endocytosis, ${ }^{33} \mathrm{FasL}$ is directly targeted from the trans-Golgi network to the secretory lysosomes. ${ }^{8}$ Depending on the stage of FasL production and recycling of classical granule markers a differential subcellular localization may result, likely also affecting the mechanism of activation-induced release of the different granule content.

Phorbol ester is known to potently activate various isoforms of the PKC family. ${ }^{20}$ As PKC not only has an important function in FasL transcription ${ }^{22,23}$ but was also reported to localize to the immunological synapse in cytotoxic T lymphocytes after contact with the target cell, ${ }^{34}$ we analyzed a possible role of PKC in activation-induced FasL degranulation. Interestingly, TCR-stimulated lytic granule exocytosis was shown to be PKC-dependent. ${ }^{24}$ Despite the use of various inhibitors of the PKC family we have not been able to demonstrate a requirement of this protein kinase family in the PMA-induced release of FasL. Similar negative results were obtained for PKA, which is also activated by PMA. ${ }^{26}$ Thus, although protein kinases are involved in the activationinduced release of preformed FasL, based on the fact that general protein kinase inhibitors block activation-induced FasL degranulation, the exact nature of these kinases currently remains enigmatic. Putative candidates may be various kinases described to interact with the proline-rich domain in the cytoplasmic tail of FasL. It was recently shown that this proline-rich domain, containing Src-homology 3 (SH3)-binding sequences, is required for the sorting of FasL to secretory lysosomes. ${ }^{8}$ Thus, molecules interacting with this proline-rich domain might also be involved in the activationinduced release of FasL to the cell surface. It is of interest that several kinases and adaptor proteins have been shown to bind to the cytoplasmic tail of FasL and to the proline-rich domain in particular. These include the Src-like kinases Fyn, Lyn, and Fgr and the adaptor proteins Nck, Grb2 and PSTPIP. ${ }^{28,35-39}$ Of interest is the recently described interaction between Nck and FasL, as Nck likely links preformed and granule-stored FasL to WASP and the cytoskeleton. ${ }^{38}$ In agreement with our observation that PMA-induced FasL degranulation was latrunculin B-sensitive it was found that the delivery of FasL to the immunological synapse was dependent on actin filament formation. ${ }^{38}$ Although there is currently no evidence available that Src-like kinases are directly involved in the sorting of FasL to secretory lysosomes, they may be important in guiding preformed and stored FasL to the cell surface and the immunological synapse, and may represent a critical link between the activation of the $T$ cell receptor and the release of granule-stored FasL.

In this study, we demonstrate that FasL can be stored in cytoplasmic granules, similar to markers of classical cytolytic lysosomes. However, the requirements for the activationinduced release of preformed FasL differ substantially from those of other markers of secretory lysosomes. Our study further suggests that protein kinase activity, rather than an increase in intracellular calcium is critical for this process. Thus, identification of the kinase(s) involved in activationinduced release of preformed FasL and the development of selective inhibitors may allow to inhibit tissue damage because of release of granule-stored FasL, for example, as observed in acute graft-versus-host disease. ${ }^{3}$

\section{Materials and Methods}

Media, cells and reagents. Primary murine and human T cells, L1210-Fas ${ }^{13}$ as well as Fas-deficient Jurkat (JOM-2) cells were cultured in IMDM supplemented with 10\% FCS, 2 mM L-Alanyl-L-glutamin, $50 \mu \mathrm{g} / \mathrm{ml}$ gentamicin (Sigma-Aldrich, St. 
Louis, MO, USA). Concavalin A, phytohemagglutinin-P (PHA-P) and the inhibitors brefeldin A, latrunculin B and K252a were purchased from Sigma-Aldrich. IL-2 (Proleukin) was from Novartis Pharma (Basel, Switzerland). IL-7, IL-15 and IFN $\gamma$ were purchased from Peprotech (Paris, France). Phorbol myristate acetate (PMA), ionomycin, bisindolylmaleimide I (Gö6850) and the myosin light chain kinase inhibitor ML-7 were from Alexis Biochemicals (San Diego, CA, USA). The protein kinase A inhibitor (myristoylated PKI amide) was from Biomol (Anawa, Wangen, Switzerland). Blebbistatin was purchased from TOCRIS Bioscience (Ellisville, MO USA). Cyclosporin A (Sandimmun) was from Novartis Pharma (Basel, Switzerland). Anti-human CD63 and CD107a, anti-murine CD107a, anti-murine FasL (clone MFL3), anti-mouse B220-biotin, anti-CD4-biotin, anti-CD4-FITC, anti-CD8-biotin and anti-CD8-FITC were purchased from BD Biosciences (San Jose, CA, USA). Anti-human FasL (clone NOK-1), anti-DX5-FITC and anti-murine CD28 were from eBioscience (San Diego, CA, USA) and anti-murine FasL (clone FLIM58) from MBL (Woburn, MA, USA). Anti-murine CD3 (clone 2C11) and anti-human CD3 (clone OKT3) were purified from hybridoma culture supernatant by protein A affinity chromatography.

Generation of murine T cell and NK cell blasts. Spleen cells from C57BL/6 mice were isolated by dissociation of the spleen between frosted microscopy glass slides, followed by hypotonic lysis to remove erythrocytes. Cells were stimulated with $2 \mu \mathrm{g} / \mathrm{ml}$ concanavalin A for 2 days in culture medium, washed and cultured with $100 \mathrm{U} / \mathrm{ml} \mathrm{IL-2} \mathrm{for} \mathrm{another} 5$ days to generate T cell blasts. To generate lymphokine-activated killer (LAK) cells, spleen cells were isolated as described above but directly cultured with $300 \mathrm{U} / \mathrm{ml}$ IL-2 for 13 days.

To generate purified $\mathrm{CD}^{+}{ }^{+}$and $\mathrm{CD} 8^{+} \mathrm{T}$ cells, spleen cells were isolated, incubated with anti-B220-biotin, washed and incubated with streptavidin-MicroBeads (Miltenyi Biotec $\mathrm{GmbH}$, Bergisch Gladbach, Germany). After washing cells were loaded on a MACS-LD column to remove $B$ cells and enrich the T cell population. Cells were stained with anti-CD4-FITC and anti-CD8-PE and sorted on a FACS Diva (BD Bioscience, San Jose, CA, USA). Purity of T cell subsets was always $>98 \%$. Purified T cells were then stimulated with plate-bound anti-CD3 $(3 \mu \mathrm{g} / \mathrm{ml}$, clone $2 \mathrm{C} 11)$ and soluble anti-CD28 $(0.5 \mu \mathrm{g} / \mathrm{ml})$. After 2 days, $100 \mathrm{U} / \mathrm{ml} \mathrm{IL-2} \mathrm{were} \mathrm{added}$ for another 5 days.

For the isolation of NK cells, spleen cells were incubated with anti-B220-biotin, anti-CD4-biotin and anti-CD8-biotin, washed and incubated with streptavidinMicroBeads. To enrich the NK cell population, cells were loaded on a MACS-LD column and $B$ and $T$ cells were removed. NK cells were then further sorted by flow cytometry using anti-DX5-FITC and anti-CD3-PE staining. Purified NK cells were cultured with $300 \mathrm{U} / \mathrm{ml} \mathrm{IL-2,} 20 \mathrm{ng} / \mathrm{ml} \mathrm{IFN-} \gamma, 5 \mathrm{ng} / \mathrm{ml} \mathrm{IL-12}$ and $10 \mathrm{ng} / \mathrm{ml} \mathrm{IL-15}$ for 7 days. NK cell purity was reconfirmed by flow cytometry before the FasL assay, and consisted of $>98 \% \mathrm{DX}^{+} \mathrm{CD}^{-}$cells.

Generation of human T cell blasts. For the generation of human T cell blasts peripheral blood mononuclear cells were isolated from buffy coat preparations of healthy donors (Swiss Red Cross, Bern, Switzerland) by FicollHypaque density gradient (GE Healthcare Europe, Otelfingen, Switzerland) centrifugation. Cells were activated with $1 \mu \mathrm{g} / \mathrm{ml} \mathrm{PHA}-\mathrm{P}$ for 2 days, followed by a 12 days culture in complete IMDM supplemented with $100 \mathrm{U} / \mathrm{ml}$ IL-2.

Functional FasL assay (cytotoxicity assay). FasL-mediated cytotoxicity assays were performed as previously described. ${ }^{13}$ Briefly, human or murine $\mathrm{T}$ cell blasts, $\mathrm{LAK}$ cells, $\mathrm{CD} 4^{+}, \mathrm{CD}^{+}$or NK cells were stimulated or not with plate-bound anti-CD3 $(1 \mu \mathrm{g} / \mathrm{ml}$ OKT3 antibody for human T cells, or $3 \mu \mathrm{g} / \mathrm{m}$ 2C11 antibody for murine T cells), PMA (20 ng/ml) or ionomycin $(500 \mathrm{ng} / \mathrm{ml})$, and incubated together with ${ }^{3} \mathrm{H}$-thymidine-labeled target cells (L1210Fas) for $6 \mathrm{~h}$ in 96-well round-bottom plates at different effector/target $(E / T)$ ratios. Cells were lysed and unfragmented DNA was harvested on Unifilter-96 GF/C glass fiber plates and counted in a $\beta$-counter (Perkin-Elmer, Boston, MA, USA). DNA fragmentation was calculated as follows: $\%$ DNA fragmentation $=100 \times(1-$ c.p.m. experimental group/c.p.m. control group). To assess the FasL specificity of the cytotoxicity assay, cells were pre-incubated with an anti-FasL blocking antibody (MFL3, $5 \mu \mathrm{g} / \mathrm{ml}$ ) for $30 \mathrm{~min}$ before the cells were stimulated and incubated with the target cells. The antibody was present throughout the entire experiment. Cells were preincubated with the indicated inhibitors for $30 \mathrm{~min}$ before stimulation and incubation with the target cells. In some experiments the specificity of PMA was tested using its inactive $\alpha$-isomere $4 \alpha$-PMA, which never induced FasL degranulation (data not shown).
Real-time PCR for FasL. Murine T cell blasts were pre-incubated with pharmacological inhibitors as indicated for $30 \mathrm{~min}$, and then stimulated or not with plate-bound anti-CD3 or PMA for $6 \mathrm{~h}$. Cells were harvested, total RNA was isolated and FasL expression was analyzed as described previously. ${ }^{40}$

\section{Generation and transfection of Fas-negative Jurkat cells} (JOM-2). Fas-deficient Jurkat cells have been generated by treating Jurkat cells for 4-6 weeks using increasing concentrations of recombinant FasL (starting from $10 \mathrm{ng} / \mathrm{ml}$ up to $2000 \mathrm{ng} / \mathrm{ml}$, Alexis). Fas-resistant cells (pool) were then sorted by flow cytometry based on the absence of Fas receptor staining, and then further amplified in the presence of FasL for 2-3 weeks. Cells were sorted again by flow cytometry for absence of Fas and corresponding clones were amplified before being positively selected based on their sensitivity to TRAIL-induced cell death.

JOM-2 Jurkat cells were transfected with a GFP-FasL expression plasmid, kindly provided by Gillian Griffith ${ }^{7,8}$, according to the optimized protocol for Jurkat cells (Amaxa Biosystems, Cologne, Germany), using the cell line Nucleofector kit $V$ and $0.5 \mu \mathrm{g}$ plasmid DNA. After transfection cells were cultured in complete medium and analyzed $16 \mathrm{~h}$ later.

Flow cytometry. GFP-FasL transfected JOM-2 cells were stimulated with PMA, ionomycin or the combination thereof, and stained extracellularly with $2 \mu \mathrm{g} / \mathrm{ml}$ anti-FasL antibody (NOK-1.1) or isotype control, followed by staining with PElabeled goat anti-mouse secondary antibody $(1: 200$, BD Biosciences, San Jose, CA, USA). For comparison, JOM-2 cells and human T cell blasts were stained with anti-CD63 or anti-CD107a antibodies followed by staining with PE-labeled goat anti-mouse secondary antibody. Staining was analyzed on a FACScan flow cytometer (BD Biosciences) and quantified using the FlowJo software (FlowJo, Ashland, OR, USA).

Intracellular staining of FasL and granule markers. Cytospins of murine $T$ cell blasts were fixed for 10 min in acetone and stained for FasL using antiFasL (clone FLIM58) or isotype control as described earlier. ${ }^{3}$ For comparison, cells were also stained for the cytotoxic granule marker CD107a. GFP-FasL transfected JO-2 cells were stained with anti-CD3 or isotype control and PE-labeled goat antimouse. In some experiments GFP-FasL transfected JOM-2 cells were also stained with anti-FasL and PE-labeled secondary antibody.

Confocal microscopy. Images were taken on a laser scan microscope (LSM 510, × 100 objective, Zeiss, Göttingen, Germany). For co-localization analysis the Imaris Coloc software (Bitplane, Zurich, Switzerland) was used.

Acknowledgements. We thank Gillian Griffiths for the GFP-FasL expression plasmid and helpful discussions, Shida Yousefi for technical advice for the confocal microscopy, Gottfried Baier for conceptual and technical support, Verena Niggli for inhibitors and the Brunner lab for precious help. This study was supported by grants from the Swiss National Science Foundation and Oncosuisse to TB.

1. Pinkoski MJ, Brunner T, Green DR, Lin T. Fas and Fas ligand in gut and liver. Am J Physiol Gastrointest Liver Physiol 2000; 278: G354-G366.

2. Siegel RM, Chan FK, Chun HJ, Lenardo MJ. The multifaceted role of Fas signaling in immune cell homeostasis and autoimmunity. Nat Immunol 2000; 1: 469-474.

3. Wasem C, Frutschi C, Arnold D, Vallan C, Lin T, Green DR et al. Accumulation and activation-induced release of preformed Fas (CD95) ligand during the pathogenesis of experimental graft-versus-host disease. J Immunol 2001; 167: 2936-2941.

4. Kavurma MM, Khachigian LM. Signaling and transcriptional control of Fas ligand gene expression. Cell Death Differ 2003; 10: 36-44.

5. Nachbur U, Kassahn D, Yousefi S, Legler DF, Brunner T. Posttranscriptional regulation of Fas (CD95) ligand killing activity by lipid rafts. Blood 2006; 107: 2790-2796.

6. Mariani SM, Matiba B, Bäumler C, Krammer PH. Regulation of cell surface APO-1/Fas (CD95) ligand expression by metalloproteases. Eur J Immunol 1995; 25: 2303-2307.

7. Bossi G, Griffiths GM. Degranulation plays an essential part in regulating cell surface expression of Fas ligand in T cells and nature killer cells. Nat Med 1999; 5: 90-96

8. Blott EJ, Bossi G, Clark R, Zvelebil M, Griffiths GM. Fas ligand is targeted to secretory lysosomes via a proline-rich domain in its cytoplasmic tail. J Cell Sci 2001; 114: 2405-2416

9. He JS, Ostergaard HL. CTLs contain and use intracellular stores of FasL distinct from cytolytic granules. J Immunol 2007; 179: 2339-2348.

10. Trambas CM, Griffiths GM. Delivering the kiss of death. Nat Immunol 2003; 4: 399-403. 
11. Lancki DW, Weiss A, Fitch FW. Requirements for triggering of lysis by cytolytic T lymphocyte clones. J Immunol 1987; 138: 3646-3653.

12. Berrebi G, Takayama H, Sitkovsky MV. Antigen-receptor interaction requirement for conjugate formation and lethal-hit triggering by cytotoxic $T$ lymphocytes can be bypassed by protein kinase C activators and Ca2+ ionophores. Proc Natl Acad Sci USA 1987; 84: 1364-1368.

13. Brunner T, Yoo NJ, La Face D, Ware CF, Green DR. Activation-induced cell death in murine $T$ cell hybridomas. Differential regulation of Fas (CD95) versus Fas ligand expression by cyclosporin A and FK506. Int Immunol 1996; 8: 1017-1026.

14. Anel A, Buferne M, Boyer C, Schmitt-Verhulst A-M, Golstein P. T cell receptor-induced fas ligand expression in cytotoxic $T$ lymphocyte clones is blocked by protein tyrosine kinase inhibitors and cyclosporin A. Eur J Immunol 1994; 24: 2469-2476.

15. Stinchcombe JC, Griffiths GM. Secretory mechanisms in cell-mediated cytotoxicity. Annu Rev Cell Dev Biol 2007; 23: 495-517.

16. Clark R, Griffiths GM. Lytic granules, secretory lysosomes and disease. Curr Opin Immunol 2003; 15: 516-521.

17. Andzelm MM, Chen X, Krzewski K, Orange JS, Strominger JL. Myosin IIA is required for cytolytic granule exocytosis in human NK cells. J Exp Med 2007; 204: 2285-2291.

18. Kagi D, Seiler P, Pavlovic J, Ledermann B, Burki K, Zinkernagel RM et al. The roles of perforin- and Fas-dependent cytotoxicity in protection against cytopathic and noncytopathic viruses. Eur J Immunol 1995; 25: 3256-3262.

19. Hahn S, Gehri R, Erb P. Mechanism and biological significance of CD4-mediated cytotoxicity. Immunol Rev 1995; 146: 57-79.

20. Griner EM, Kazanietz MG. Protein kinase $C$ and other diacylglycerol effectors in cancer Nat Rev Cancer 2007; 7: 281-294.

21. Abraham I, Wolf CL, Sampson KE, Laborde AL, Shelly JA, Aristoff PA et al. K252a, KT5720, KT5926, and U98017 support paclitaxel (taxol)-dependent cells and synergize with paclitaxel. Cancer Res 1994; 54: 5889-5894.

22. Villunger A, Ghaffari-Tabrizi N, Tinhofer I, Krumbock N, Bauer B, Schneider T et al. Synergistic action of protein kinase $C$ theta and calcineurin is sufficient for Fas ligand expression and induction of a crmA-sensitive apoptosis pathway in Jurkat $T$ cells. Eur J Immunol 1999; 29: 3549-3561.

23. Villalba M, Kasibhatla S, Genestier L, Mahboubi A, Green DR, Altman A. Protein kinase ctheta cooperates with calcineurin to induce Fas ligand expression during activationinduced T cell death. J Immunol 1999; 163: 5813-5819.

24. Grybko MJ, Pores-Fernando AT, Wurth GA, Zweifach A. Protein kinase C activity is required for cytotoxic $T$ cell lytic granule exocytosis, but the theta isoform does not play a preferential role. J Leukoc Biol 2007; 81: 509-519.

25. Gekeler V, Boer R, Uberall F, Ise W, Schubert C, Utz I et al. Effects of the selective bisindolylmaleimide protein kinase C inhibitor GF 109203X on P-glycoprotein-mediated multidrug resistance. Br J Cancer 1996; 74: 897-905.
26. Baillie G, MacKenzie SJ, Houslay MD. Phorbol 12-myristate 13-acetate triggers the protein kinase A-mediated phosphorylation and activation of the PDE4D5 cAMP phosphodiesterase in human aortic smooth muscle cells through a route involving extracellular signal regulated kinase (ERK). Mol Pharmacol 2001; 60: 1100-1111.

27. Dell'Acqua ML, Scott JD. Protein kinase A anchoring. J Biol Chem 1997; 272 $12881-12884$

28. Qian J, Chen W, Lettau M, Podda G, Zornig M, Kabelitz D et al. Regulation of FasL expression: a SH3 domain containing protein family involved in the lysosomal association of FasL. Cell Signal 2006; 18: 1327-1337.

29. Kessler B, Hudrisier D, Schroeter M, Tschopp J, Cerottini JC, Luescher IF. Peptide modification or blocking of CD8, resulting in weak TCR signaling, can activate CTL for Fas- but not perforin-dependent cytotoxicity or cytokine production. J Immunol 1998; 161 6939-6946.

30. Brossart P, Bevan MJ. Selective activation of fas/fas ligand-mediated cytotoxicity by a self peptide. J Exp Med 1996; 183: 2449-2458.

31. Cao W, Tykodi SS, Esser MT, Braciale VL, Braciale TJ. Partial activation of CD8+ T cells by a self-derived peptide. Nature 1995; 378: 295-298.

32. Kataoka T, Shinohara N, Takayama H, Takaku K, Kondo S, Yonehara S et al. Concanamycin A, a powerful tool for characterization and estimation of contribution of perforin- and Fas-based lytic pathways in cell- mediated cytotoxicity. J Immunol 1996; 156 3678-3686

33. Blott EJ, Griffiths GM. Secretory lysosomes. Nat Rev Mol Cell Biol 2002; 3: 122-131.

34. Faroudi M, Utzny C, Salio M, Cerundolo V, Guiraud M, Muller S et al. Lytic versus stimulatory synapse in cytotoxic $T$ lymphocyte/target cell interaction: manifestation of a dual activation threshold. Proc Natl Acad Sci USA 2003; 100: 14145-14150.

35. Hane M, Lowin B, Peitsch M, Becker K, Tschopp J. Interaction of peptides derived from the Fas ligand with the Fyn-SH3 domain. FEBS Lett 1995; 373: 265-268.

36. Janssen O, Qian J, Linkermann A, Kabelitz D. CD95 ligand - death factor and costimulatory molecule? Cell Death Differ 2003; 10: 1215-1225.

37. Wenzel J, Sanzenbacher R, Ghadimi M, Lewitzky M, Zhou Q, Kaplan DR et al. Multiple interactions of the cytosolic polyproline region of the CD95 ligand: hints for the reverse signal transduction capacity of a death factor. FEBS Lett 2001; 509: 255-262.

38. Lettau M, Qian J, Linkermann A, Latreille M, Larose L, Kabelitz D et al. The adaptor protein Nck interacts with Fas ligand: guiding the death factor to the cytotoxic immunological synapse. Proc Natl Acad Sci USA 2006; 103: 5911-5916.

39. Zuccato E, Blott EJ, Holt O, Sigismund S, Shaw M, Bossi G et al. Sorting of Fas ligand to secretory lysosomes is regulated by mono-ubiquitylation and phosphorylation. J Cell Sci 2007; 120: 191-199.

40. Wasem C, Arnold D, Saurer L, Corazza N, Jakob S, herren S et al. Sensitizing antigenspecific CD8+ T cells for accelerated suicide causes immune incompetence. J Clin Invest 2003; 111: 1191-1199. 